high proportion of these to be in contact with the treatment services.

Planning must take account of the necessity of providing continued access for new patients without undue delay, while recognising that many patients will require recurrent or long-term periods of therapy.

In rural areas, which often entail the provision of services in widely disseminated small towns, particular arrangements may be necessary. The measures may include treatment by general mental health professionals, who would receive guidance from specialist district and regional services.

\section{Care outside NHS facilities}

Access to longer term rehabilitation depends upon the close working relationship from the specialist NHS services. Co-operative action with health authority and local authority social service departments is needed to provide core funding for non-statutory projects, with top-up funding through the local authorities for individual drug users who require residential rehabilitation in hostels.

\section{Record keeping}

It is important that record-keeping both in statutory and non-statutory drug agencies is of a high standard to allow evaluation of the service and to provide an early awareness of new drug problems. Data must be stored in a form that permits comparison between projects or districts so as to permit meaningful regional analysis of this information. This will require adequate and precisely allotted secretarial and clerical support for psychiatric and paramedical staff.

\section{Training long-term arrangements}

Many kinds of staff require expanded provision for training. There is a shortage of senior registrars in psychiatry who are adequately trained to take over consultant responsibility for drug dependence services. Each rotational scheme for senior registrars should contain an approved placement for substance misuse that includes experience with drug misusers. Registrar rotations should also provide shorter-term experience and instruction in the assessment and care of drug misusers. For further information on senior registrar training requirements see Report from Royal College of Psychiatrists, 1989.

The district drug consultant, in collaboration with regional drug services, should ensure that training is provided for a wide range of health and other professions, in particular:

general practitioners: in conjunction with postgraduate deans with university departments of general practice and with regional advisers of the Royal College of General Practitioners. Clinical assistant or hospital practitioner appointments provide a useful means of developing a pool of general practitioners.

specialist drug nurses

social workers

probation officers

The need for special funding that is additional to the existing local training budgets for health personnel, social workers and probation officers should be agreed and implemented by the respective budget holders.

\section{Training - urgent action required}

Until there is an adequate number of senior psychiatric registrars with appropriate training, there is an immediate need for some general psychiatrists to divert identified sessions to drug misuse. They require a period of attachment (whole-time or part-time) to an established drug dependence service. The expansion of treatment services for drug dependence, including the diversion of general psychiatrists requires additional general psychiatric consultant posts.

Approved by Council

March 1989

\title{
The Membership Examination
}

We have been asked by the Court of Electors to remind all candidates who present themselves at the College's Examinations that they are expected to observe scrupulously the normal examination conventions at all times. Two specific points need particular attention:

\section{(1) The Written Examinations}

Candidates are expected to take care that they follow precisely and promptly all instructions given by invigilators. In particular, they should stop writing immediately they are told to do so, even if this should mean a sentence remains incomplete. Any candidates 
who fail to do so must understand that they are liable to disqualification.

(2) The Clinical Examination

It is necessary at this stage to emphasise the following recent amendment to the Guidelines which are issued to candidates:

"Prior to their Clinical Examination, candidates should not visit the Hospital to which they have been allocated, either to see patients or for any other purpose relevant to their forthcoming Examination. Any queries concerning this should be addressed to the College of Examinations Officer."

The Court of Electors rightly demands that all candidates should show impeccable standards of behaviour during the College Examinations. Any deviation from these could be a matter of disqualification, not only from the current Examination but also from acceptance as a candidate at any time subsequently.
H. G. MORGAN
A. C. P. Sims
Chief Examiner
Dean

\section{The training required to provide a psychiatric service for children and adolescents with mental handicaps}

This report has been written by a Joint Working Party between the Section for the Psychiatry of Mental Handicap and the Child and Adolescent Psychiatry Section which was convened to consider the issues involved in providing a psychiatric service for children and adolescents with mental handicaps.*

\section{Current practice}

To assess current practice and opinion, a postal questionnaire was circulated to 712 members of both Specialist Sections.

Thirty-eight per cent of those working in mental handicap and $49 \%$ of child and adolescent psychiatrists replied, a total of 347 returns.

A quarter of the replies from the psychiatrists in mental handicap showed that they were prepared to offer a service from birth while the rest had a lower age limit which differed widely from 1 to 20 years.

An upper age limit of 17 to 18 years was most commonly operated by child and adolescent psychiatrists with $20 \%$ prepared to see older patients; $22 \%$ took 16 to be the upper age limit though a few were only prepared to see younger children.

Thirty-two per cent of consultant child and adolescent psychiatrists offered a service to children with severe mental handicap but $80 \%$ treated children with mild mental handicap.

Severely handicapped children were treated by $70 \%$ of the psychiatrists in mental handicap but less than $59 \%$ saw those with mild handicap.

-Members of the Working Party: Dr Sheila Hollins (Convenor), Professor Rory Nicol, Professor B. Sacks, Dr Yvonne Wiley (MHPSAC), Dr Tom Berney, and Dr Ann Gath (CAPSAC).
Respondents who did not provide a service themselves were asked who did. Paediatricians were thought by $28 \%$ of both specialities to be filling the gap. It is salutary to note that nine psychiatrists in mental handicap and 22 child psychiatrists replied that there was no psychiatric service for children and adolescents with mental handicap.

\section{Adequacy of current training}

Of those senior registrars/lecturers whose training was primarily in mental handicap, only $23 \%$ felt their training was adequate to offer a service to children with mild learning difficulties and $31 \%$ to treat children with severe learning difficulties. Among the child psychiatry trainees, $62 \%$ were adequately prepared for mild learning difficulties but only $13 \%$ for severe.

Senior registrars being trained in both mental handicap and child psychiatry settings, $7 \%$ of the total, replied that $67 \%$ were satisfied with their training for mild learning difficulties and $60 \%$ for severe learning difficulties. These results point to the advantage of joint training initiatives.

\section{Comments on present provision of service}

Specialists in Mental Handicap and Child and Adolescent Psychiatry provide a complementary service which ideally would be over-lapping but, because of inadequate consultant provision, tend to be overstretched. Some psychiatrists in mental handicap are 'Jacks of all Trades', but others find their administrative role, for example, in hospital resettlement work, 